\title{
Focus on the frail and elderly: who should have a trial of ICU treatment?
}

\author{
Otavio T. Ranzani ${ }^{1,2^{*}}$ (D, Bruno A. M. P. Besen ${ }^{3}$ and Margaret S. Herridge ${ }^{4}$
}

๑ 2020 Springer-Verlag GmbH Germany, part of Springer Nature

Very old intensive care patients (VIPs $\geq 80$ years of age) are vulnerable. They may deteriorate and develop multiple organ dysfunction rapidly, before having clarified their explicit goals of care to their caretakers and without an understanding of longer term patient-centered outcomes [1-3]. Intensive care unit (ICU) admission of such patients 'just for monitoring' may culminate in clinical deterioration before determination of the direction of future care. VIPs are subject to different triage practices across ICUs $[1,2,4]$. This underscores the need to determine which VIP might benefit from ICU admission and how such decisions may be informed by patient preferences and societal preferences for elderly and ageing patients $[1,2,5,6]$.

Recent trials underscore the challenges of risk-stratifying patients based solely on age. A cluster-randomized trial evaluated whether recommending systematic ICU admission for patients older than 75 years would result in lower long-term mortality [4]. The trial showed a higher proportion of ICU admissions for elderly patients compared to usual care, but this practice was associated with an increased risk of long-term mortality in the intention-to-treat analysis [1, 4]. In contrast, two recent observational studies using causal inference, showed the potential for short-term mortality benefit of ICU admission [7, 8] in elderly patients with pneumonia [7]. The two key patient characteristics associated with poor outcomes in these studies were the presence of an underlying malignancy and disability at the time of ICU admission [2]. Of note, patients included in the cited

\footnotetext{
*Correspondence: otavioranzani@yahoo.com.br

1 Pulmonary Division, Laboratório de Pneumologia, Heart Institute (InCor), Hospital das Clinicas HCFMUSP, Faculdade de Medicina, Universidade de Sao Paulo, $2^{\circ}$ andar, sala 2144, Av. Dr. Arnaldo, 455, São Paulo, São Paulo 01246903, Brazil

Full author information is available at the end of the article
}

cluster-randomized trial had a median age of 85 years [1], but were functionally independent (i.e., Index of Independence in Activities of Daily Living Score of $\geq 4$ or not evaluable), free from cancer and nutritionally preserved (i.e. absence of cachexia, subjectively assessed by physicians at the bedside) $[9,10]$. Factors that portend a more favorable outcome may be more often present in elderly patients admitted to the ICU. This could reflect an intense selection bias toward the high functioning elderly to justify ICU treatment [9].

Aiming to better delineate prognosis in the elderly, frailty has often been proposed as a good candidate tool for ICU triage $[1,10]$. Frailty is a syndrome characterized by high vulnerability and low organ reserve [11]. There have been important developments in the evaluation of frailty prior to ICU admission, including the creation of bedside tools to facilitate rapid assessment [10]. Despite the availability of better tools for evaluating frailty, some important issues remain unresolved regarding their applicability. These include the need to determine robust construct and criterion validity for these tools in critically-ill patients, the generalizability of a score originally derived from ambulatory/"stable" patients to those with life-threatening illness, and the problems related to identification of a syndrome rather than a distinct disease $[9,10]$. One of the greatest challenges at this time is how to identify "silent frailty" using the geriatric concept of homeostenosis (i.e., normal ageing/senescence results in diminished physiologic reserves that are needed to balance challenges to homeostasis) [7] (see Fig. 1).

The ICU clinician wishes to "first do not harm". ICU admission or non-admission of frail, elderly, critically-ill patients may represent a source of discomfort and moral distress. If defining the threshold for a good balance between under- and over-treatment is difficult for a general ICU patient, it is even more challenging for the old. In this scenario, a time-limited trial (TLT) of treatment

\section{Springer}




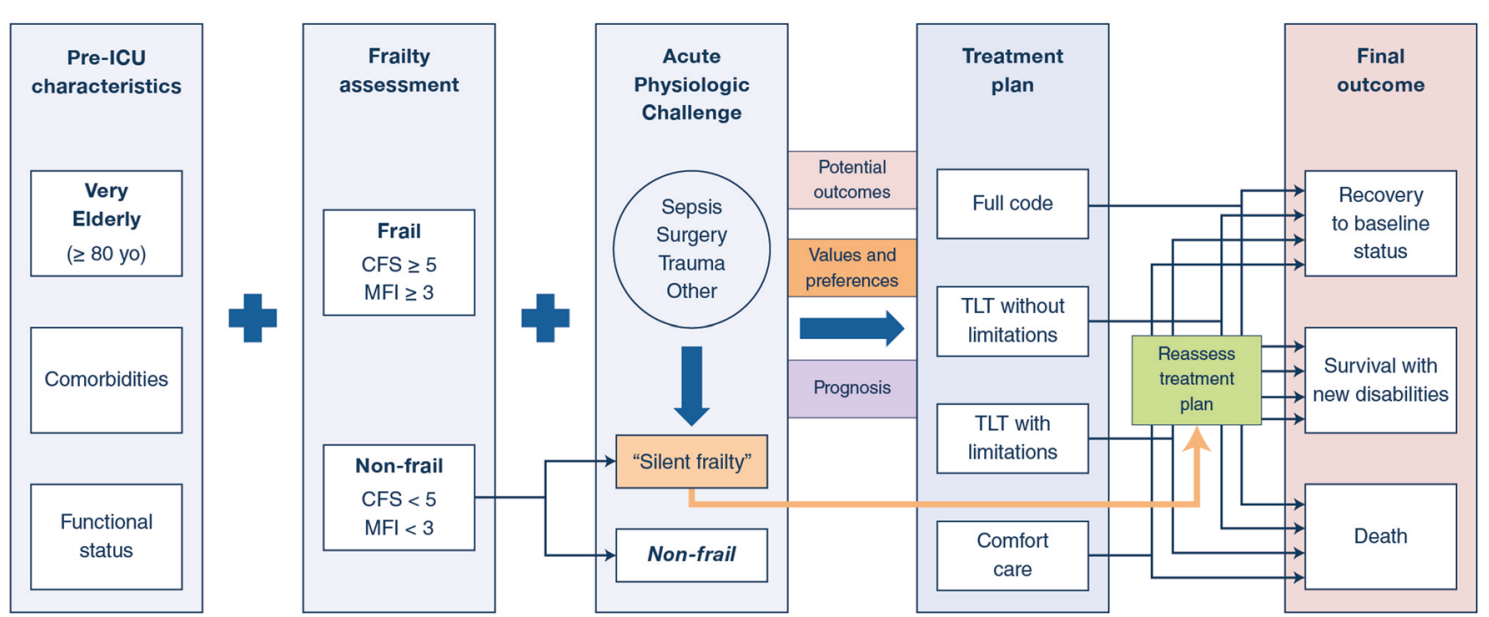

Fig. 1 Diagram illustrating the potential pathways for elderly and frail patients after ICU admission. In the evaluation of a very elderly patient, functional status and previous comorbidities should be assessed, but frailty must be added to risk stratification. In the face of an acute physiological challenge, the frail patient will portend worse outcomes. This, in line with the patient's values and preferences, considering the baseline prognosis of the patient and accounting for a realistic potential outcome, should guide the treatment plan in an attempt to achieve the best feasible final outcome. Silent frailty refers to a potentially frail patient not captured by currently studied frailty scales in ICU or for those patients that, after an acute challenge, suddenly appear to be frail. We hypothesize that silent frailty becomes evident with the physiological challenge of an acute systemic insult and may change decision-making at the bedside according to the patient's ICU course. This would urge the compulsory reassessment of the initial treatment plan, which could not anymore be in line with patient's values. One must note that different frailty scales capture different domains of the frailty syndrome, while the CFS is based on levels of function, MFI mainly represents multi-comorbidity, so they are not interchangeable [10, 11]. Additionally, diagnostic cut-off values may have different clinical utility on different contexts [10, 11]. TLT time-limited trial, CFS Clinical Frailty Scale, MFI Modified Frailty Index

may be a welcome compromise. The principles of TLT have been summarized in a recent review that also highlights the challenges of assessing the appropriateness and the ethics of such an approach [3]. The suggestions provided for implementing a TLT are its application in patients with an uncertain prognosis and/or unclear preferences; comprehensive discussion with patient/family both before and during ICU admission to facilitate an understanding of patient preferences and expectations; individualization of the optimal duration of the TLT and agreement on the time for reevaluation and prospective determination of a modest list of treatment goals established by the multidisciplinary team as a whole [3]. The main tenet of this approach is the commitment to clear communication within and between health care teams and patient and family members. This will enable discussion about withholding/withdrawing therapies that may be potentially harmful or inappropriate.

The challenges to implementing TLT are further compounded by the variation in withholding/withdrawing practice by country, cultural belief and individual clinician's perspective/values. These were illustrated in a multicenter European study showing that limitations on life-sustaining therapies occurred in about one-third of very old patients in 309 ICUs from 21 countries. The study highlighted important variability depending on patient and country characteristics, suggesting that opinions and practices about how the limitation of lifesustaining therapies should be applied may differ [12]. Therefore, alternatives to ICU admission should also be discussed, including other treatment dispositions such as geriatric wards and intermediate care units.

Variability in the limitation of life-sustaining therapies for elderly patients is also observed in the presence of specific pre-existing conditions almost synonymous with bleak outcomes. In a cohort of old patients with severe acute kidney injury in Canada, the decision for renal replacement therapy was largely influenced by patientspecific factors and by clinician perception of benefit [13]. Young patients who experience cardiac arrest have generally poor outcomes. The prognosis for most elderly patients after cardiac arrest may be dismal. This dilemma has been discussed recently for the VIP, and more research and ethical debate is urgently needed on this topic $[5,14]$.

\section{Future perspectives}

Age remains an important surrogate for organ reserve and resilience. However, advances in our understanding and assessment of frailty can help to further risk stratify and prognosticate vulnerable populations [15]. Indeed, frailty-measured by the clinical frailty scale-has 
recently been shown to be one of the best tools to characterize an elderly patient [16]. While there have been important advances in critical care, we are still challenged to discern which elderly patients may benefit most from this cost-intensive treatment and how best to operationalize shared decision-making. It is crucial that patient-centred outcomes of functional disability and quality of life become central to outcome studies rather than solely survival. TLT seems to be a balanced compromise, but we still have fundamental questions about how to identify those patients with an uncertain prognosis, when to reevaluate the initial decision and how to adapt this model to different cultures globally. We also need to more fully understand whether non-invasive or less aggressive approaches are more suitable to achieve shared treatment goals for the elderly and frail. These may include the use of non-invasive ventilation or highflow oxygen, lower mean arterial pressure targets or a watch-and-wait strategy for acute kidney injury.

\author{
Author details \\ 1 Pulmonary Division, Laboratório de Pneumologia, Heart Institute (InCor), \\ Hospital das Clinicas HCFMUSP, Faculdade de Medicina, Universidade de Sao \\ Paulo, $2^{\circ}$ andar, sala 2144, Av. Dr. Arnaldo, 455, São Paulo, São Paulo 01246903 , \\ Brazil. ${ }^{2}$ Barcelona Institute for Global Health, ISGlobal, Barcelona, Spain. \\ ${ }^{3}$ Medical Intensive Care Unit, Hospital das Clinicas HCFMUSP, Faculdade de \\ Medicina, Universidade de Sao Paulo, São Paulo, Brazil. ${ }^{4}$ Interdepartmental \\ Division of Critical Care Medicine, Institute of Medical Science, Toronto General \\ Research Institute, University of Toronto, Toronto, Canada.
}

\section{Author contributions}

All the authors developed the outline. OTR wrote the first draft. All the authors contributed to the critical revision of the manuscript for important intellectual content.

\section{Funding \\ None.}

\section{Compliance with ethical standards}

\section{Conflicts of interest}

OTR is on the Editorial Board for ICM and declares no competing interests. $\mathrm{BAMPB}$ and $\mathrm{MH}$ declare no competing interests.

\section{Publisher's Note}

Springer Nature remains neutral with regard to jurisdictional claims in published maps and institutional affiliations.

Received: 7 November 2019 Accepted: 7 February 2020 Published online: 2 March 2020

\section{References}

1. Guidet B, de Lange DW, Flaatten H (2018) Should this elderly patient be admitted to the ICU? Intensive Care Med 44:1926-1928

2. Flaatten $H$, de Lange DW, Artigas $A$, Bin D, Moreno $R$, Christensen S, Joynt GM, Bagshaw SM, Sprung CL, Benoit D, Soares M, Guidet B (2017) The status of intensive care medicine research and a future agenda for very old patients in the ICU. Intensive Care Med 43:1319-1328
3. Vink EE, Azoulay E, Caplan A, Kompanje EJO, Bakker J (2018) Time-limited trial of intensive care treatment: an overview of current literature. Intensive Care Med 44:1369-1377

4. Guidet B, Leblanc G, Simon T, Woimant M, Quenot JP, Ganansia O, Maignan M, Yordanov Y, Delerme S, Doumenc B, Fartoukh M, Charestan P, Trognon P, Galichon B, Javaud N, Patzak A, Garrouste-Orgeas M, Thomas C, Azerad S, Pateron D, Boumendil A, Network I-CS (2017) Effect of systematic intensive care unit triage on long-term mortality among critically ill elderly patients in France: a randomized clinical trial. JAMA 318:1450-1459

5. Forte DN, Kawai F, Cohen C (2018) A bioethical framework to guide the decision-making process in the care of seriously ill patients. BMC Med Ethics 19:78

6. Flaatten $\mathrm{H}$, Oeyen S, deLange DW (2018) Predicting outcomes in very old ICU patients: time to focus on the past? Intensive Care Med 44:1344-1345

7. Valley TS, Sjoding MW, Ryan AM, Iwashyna TJ, Cooke CR (2015) Association of intensive care unit admission with mortality among older patients with pneumonia. JAMA 314:1272-1279

8. Harris S, Singer M, Sanderson C, Grieve R, Harrison D, Rowan K (2018) Impact on mortality of prompt admission to critical care for deteriorating ward patients: an instrumental variable analysis using critical care bed strain. Intensive Care Med 44:606-615

9. Zampieri FG, Iwashyna TJ, Viglianti EM, Taniguchi LU, Viana WN, Costa R, Correa TD, Moreira CEN, Maia MO, Moralez GM, Lisboa T, Ferez MA, Freitas CEF, de Carvalho CB, Mazza BF, Lima MFA, Ramos GV, Silva AR, Bozza FA, Salluh JIF, Soares M, Investigators OS (2018) Association of frailty with short-term outcomes, organ support and resource use in critically ill patients. Intensive Care Med 44:1512-1520

10. Flaatten $\mathrm{H}$, Clegg A (2018) Frailty: we need valid and reliable tools in critical care. Intensive Care Med 44:1973-1975

11. Muscedere J, Waters B, Varambally A, Bagshaw SM, Boyd JG, Maslove D, Sibley S, Rockwood K (2017) The impact of frailty on intensive care unit outcomes: a systematic review and meta-analysis. Intensive Care Med 43:1105-1122

12. Guidet $B$, Flaatten $H$, Boumendil A, Morandi A, Andersen FH, Artigas A, Bertolini G, Cecconi M, Christensen S, Faraldi L, Fjolner J, Jung C, Marsh B, Moreno R, Oeyen S, Ohman CA, Pinto BB, Soliman IW, Szczeklik W, Valentin A, Watson X, Zafeiridis T, De Lange DW, Group VIPs (2018) Withholding or withdrawing of life-sustaining therapy in older adults ( $\geq 80$ years) admitted to the intensive care unit. Intensive Care Med 44:1027-1038

13. Bagshaw SM, Adhikari NKJ, Burns KEA, Friedrich JO, Bouchard J, Lamontagne F, Mclntrye LA, Cailhier JF, Dodek P, Stelfox HT, Herridge M, Lapinsky S, Muscedere J, Barton J, Griesdale D, Soth M, Ambosta A, Lebovic G, Wald R, Canadian Critical Care Trials G (2019) Selection and receipt of kidney replacement in critically ill older patients with AKI. Clin J Am Soc Nephrol 14:496-505

14. Mentzelopoulos SD, Slowther AM, Fritz Z, Sandroni C, Xanthos T, Callaway C, Perkins GD, Newgard C, Ischaki E, Greif R, Kompanje E, Bossaert L (2018) Ethical challenges in resuscitation. Intensive Care Med 44:703-716

15. Herridge MS, Chu LM, Matte A, Tomlinson G, Chan L, Thomas C, Friedrich JO, Mehta S, Lamontagne F, Levasseur M, Ferguson ND, Adhikari NK, Rudkowski JC, Meggison H, Skrobik Y, Flannery J, Bayley M, Batt J, Santos CD, Abbey SE, Tan A, Lo V, Mathur S, Parotto M, Morris D, Flockhart L, Fan E, Lee CM, Wilcox ME, Ayas N, Choong K, Fowler R, Scales DC, Sinuff T, Cuthbertson BH, Rose L, Robles P, Burns S, Cypel M, Singer L, Chaparro C, Chow CW, Keshavjee S, Brochard L, Hebert P, Slutsky AS, Marshall JC, Cook D, Cameron JI, Investigators RP, Canadian Critical Care Trials G (2016) The RECOVER program: disability risk groups and 1-year outcome after 7 or more days of mechanical ventilation. Am J Respir Crit Care Med 194:831-844

16. Guidet B, de Lange DW, Boumendil A, Leaver S, Watson X, Boulanger C, Szczeklik W, Artigas A, Morandi A, Andersen F, Zafeiridis T, Jung C, Moreno R, Walther S, Oeyen S, Schefold JC, Cecconi M, Marsh B, Joannidis M, Nalapko Y, Elhadi M, Fjolner J, Flaatten H, Group VIPs (2020) The contribution of frailty, cognition, activity of daily life and comorbidities on outcome in acutely admitted patients over 80 years in European ICUs: the VIP2 study. Intensive Care Med 46:57-69 